\title{
Cefaleia relacionada ao uso do EPI durante a pandemia do COVID-19 em cirurgiões dentistas
}

\author{
Isabela Coelho Novaes ${ }^{1}$ (D), Camila Maria Bastos Machado de Resende ${ }^{2}$ (D), Karen Oliveira Peixoto ${ }^{2}$ (D), \\ Erika Oliveira de Almeida² (D), Gustavo Augusto Seabra Barbosa² ${ }^{\text {(D) }}$, Yuri Martins Costa' ${ }^{1 D}$, \\ Juliana Stuginski-Barbosa ${ }^{3}$
}

\author{
'Faculdade de Odontologia de Piracicaba Universidade Estadual de Campinas, Piracicaba, SP, Brasil. \\ 2Universidade Federal do Rio Grande do Norte (UFRN), Natal, RN, Brasil \\ 3Universidade de São Paulo, Bauru, São Paulo, Brasil
}

\begin{abstract}
A pandemia de Covid-19 trouxe um aumento do uso de equipamentos de proteção individual (EPI) pelos profissionais da saúde, além de um aumento do relato de episódios de cefaleia. Dessa forma, esse estudo verificou a presença e as características da cefaleia pelo uso de EPI em cirurgiões-dentistas (CD) durante a pandemia de COVID-19. Foram incluídos 641 CD que responderam a um formulário eletrônico contendo: Questionário de triagem de dor para Disfunções Temporomandibulares, Índice de Qualidade do Sono de Pittsburgh, Escala de Depressão, Ansiedade e Estresse e questões sobre as características da cefaleia durante a pandemia. Para análise estatística o método de regressão logística foi utilizado considerando um nível de significância de 5\%. Foi observado que 40,38\% dos pacientes possuíram algum tipo de cefaleia possivelmente relacionada ao uso do EPI. Desses, $51,18 \%$ relataram dor na região temporal e parietal, $41,76 \%$ na região frontal, $21,18 \%$ na occipital, 15,88\% orbital, 14,12\% no topo da cabeça e 9,41 em toda a cabeça. Em 82,35\% dos pacientes a cefaleia foi bilateral e as características mais comuns foram dor em pressão (67,06\%) e latejante/pulsátil (30\%). Em relação a intensidade, $41,17 \%$ apresentaram uma cefaleia leve, $57,65 \%$ moderada e $0,59 \%$ severa. Houve uma associação da ocorrência de cefaleia devido ao uso de EPI com as variáveis: sexo, idade, ansiedade e sintomas de DTM. Também foi verificado que profissionais do gênero feminino possuíram uma chance 4,2 maior de apresentar cefaleia. Além disso, a chance do profissional com idade até 40 anos, apresentar cefaleia foi 1,7 vezes maior em comparação aos profissionais com idade superior. Em contrapartida, em profissionais sem sintomas de ansiedade, a chance de apresentar cefaleia diminui $53 \%$ e a chance do profissional sem sintomas de DTM apresentar cefaleia, diminui em 53\%. Uma possível cefaleia pelo uso de EPI é fenotipicamente semelhante à cefaleia do tipo tensional.
\end{abstract}

Palavras-chave: Pandemia Covid19, Cirurgiões-Dentistas, Cefaleia, EPIs. 